\title{
Growth patterns of yearling steers determined from daily live weights
}

\author{
PAT O. CURRIE, JERRY D. VOLESKY, DON C. ADAMS, AND BRADFORD W. KNAPP
}

\section{Abstract}

Growth patterns for free-ranging yearling steers were quantified from daily live weights obtained with automatic scales which animals entered to obtain drinking water. Forty steers were monitored during each summer grazing period of 1986 and 1987. Frequency of watering and, thus, weighing on the automatic scales averaged 2.4 times/day. Significant $(p<0.01)$ quadratic relationships between live weight and Julian date were obtained. In 1986, predicted live weight of the steers peaked in late July to early August and then decreased through to the end of the grazing period in September. Live weight of the steers in 1987 followed a similar pattern although the late summer decrease was not as great as in 1986. When animals were periodically weighed using manual procedures, a lower rate of gain was measured in the second half than in the first half of the summer graxing period every year from 1983 through 1987 . However, we were unable to specifically identify when these weight changes occurred until the automatic scales were used in 1986 and 1987. The automatic weighing equipment documented substantial within-day live weight variability among steers. This variability changed over the grazing period on a dayto-day basis. Within-day variability must be considered when establishing manual weighing schedules with conventional equipment. Live weight data in conjunction with other measurements will permit development of a more comprehensive animal-plantclimate model.

Key Words: automated weighing equipment, sampling methods, growth models

Growth and productivity of free-ranging herbivores is assessed most often by periodically weighing animals at various time intervals. However, length of interval between weighings can affect interpretive conclusions about temporal changes in live weight gains because it dictates the number of data points available for analyses. For example, rate of gain of yearling animals has been observed to consistently decline over a growing season in conjunction with declines in forage quality (Hart et al. 1983, Jung et al. 1985, Volesky 1986). Although this gradual decline in rate of gain over time is described generally as a quadratic relationship, the relationship has never been very precisely defined because of our inability to obtain daily live weight data without excessive animal handling.

Another major problem affecting interpretive conclusions based on temporal changes or differences in animals weights is rumen fill (Hart 1987). In early studies, variations in weights due to temporal variation in amount of rumen fill were minimized by using average live weights taken 2 or 3 days in succession to estimate daily gain (Lush and Black 1927). Later studies showed, however, that statistical variation was often reduced more by increasing numbers of animals per treatment and weighing them once rather than having

\footnotetext{
Currie is range scientist, Adams is range animal nutritionist, and Knapp is statistician, USDA-ARS. At the time of the research, Volesky was research associate, Montana Agricultural Experiment Station at the Fort Keogh Livestock and Range Research Station, Route 1, Box 2021, Miles City, Mont. 59301. Volesky is currently range animal scientist, USDA-ARS, Forage and Livestock Research Lab., P.O. Box 1199, El Reno, Okla. 73036.

This study is a contribution from the U.S. Department of Agriculture, Agricultural Research Service, and Montana Agriculture Experiment Station, Miles City, Mont., Joumal Series No. J-2232.

Manuscript accepted 23 January 1989.
}

fewer animals and weighing them on successive days (Johnson and Laycock 1963, Hughes 1976). More recently, employment of overnight shrinks as a means to reduce the effects of rumen fill on live weights has been used (Hughes 1976). However, weight loss during a period of shrink has been shown to not be consistent within a year. Anderson and Tietjen (1982) and Heitschmidt (1982) concluded length of shrink, forage, and environmental conditions must be similar in order to standardize the measurement of range cow weights.

In an attempt to better quantify seasonal live weight gains of cattle, an automatic scale which delivers water to the animal while it is on the scale was developed to weigh individual animals each time they watered (Anderson 1981, Adams et al. 1987). The purpose of this paper is to describe live weight patterns of free-ranging yearling steers using daily live weights obtained from this newly developed scale system (Adams et al. 1987). Results are described in reference to potential usefulness and applicability to a comprehensive animal-plant-climate model.

\section{Material and Methods}

The research was conducted during 1986 and 1987 at the Fort Keogh Livestock and Range Research Laboratory located near Miles City, Montana. Long-term annual precipitation at Miles City averaged $35 \mathrm{~cm}$ from 1936 to 1987 . Annual precipitation was $41 \mathrm{~cm}$ in 1986 and $31 \mathrm{~cm}$ in 1987 . The study was made on 8 pastures each of which was approximately 12 ha in size. These pastures were established in 1982 on a fair to poor condition range site. Vegetation in the pastures in 1982 was a mixture of western wheatgrass (Pascopyrum smithii (Rydb.) Love), Sandberg bluegrass (Poa sandbergii Vasey), blue grama (Bouteloua gracilis H.B.K. Lag. ex Griffiths), cheatgrass (Bromus tectorum L.), and big sagebrush (Artemisia tridentata Pursh.). In 1982, 6 of the 8 pastures were treated with a prototype Range Improvement Machine (RIM) (Erickson and Currie 1985) or a combination of treatments using the RIM, nitrogen fertilizer, legume interseeding, or brush control. Further descriptions of the RIM and pasture treatments are given by Currie and Volesky (1987).

Each year, a minimum total of 40 cross-bred yearling steers were assigned to the 8 different pastures. During the 1986 trial (9 June 10 September) 5 yearling steers continuously grazed 6 of the pastures whereas 10 steers alternately grazed 2 of the pastures. During the 1987 trial (1 June to 1 September), the initial number of steers per pasture was the same as in 1986 . However, numbers were varied later in the grazing period as put-and-take animals were used to equalize grazing pressure among experimental pastures. Average initial weights of the steers were 338 and $319 \mathrm{~kg}$ in 1986 and 1987 , respectively.

Seven automatic scale units were used in the study. All units were designed so animals had to enter individually to gain access to drinking water. An individual's live weight was continuously recorded for as long as the animal was in the unit. Weights were averaged every 3 seconds and stored in computer Random Access Memory (RAM) for daily transmission via radio signal to storage in a central computer located approximately $10 \mathrm{~km}$ away. Quantity 
of water consumed, expressed as a weight, served as a cross-check for changes in animal live weight from the time an animal first entered the scale to when it left. A more detailed description of the system and its peripherals is given by Adams et al. (1987).

All steers underwent a 2- to 3-week training period with the scales in drylot prior to starting the grazing trials. Animals which were reluctant or refused to enter the scales for water during this period were culled. For comparative purposes, all steers were also manually weighed on a 'conventional' scale at the beginning, midpoint, and end of each grazing period. The conventional scale was a chute suspended from electronic load-cells with an electronic readout. Linear and nonlinear regression analyses were used to evaluate and quantify daily live weight changes in relation to Julian date. The minimum daily live weight recorded for each individual animal was used in the regression analyses.

\section{Results and Discussion}

\section{Steer Activities}

Most animals learned relatively quickly how to use the scale units as their sole source for drinking water. Less than $5 \%$ of the steers were culled each year for lack of adaptation or problems with disposition which interfered with use of the scales. Electrical and mechanical performance of the scale equipment was generally trouble free during the 2-year study. Free-water that had ponded in some of the experimental pastures after heavy rainstorms limited the use of the scales by animals for short periods each year.

Frequency of watering and thus use of the automatic scales averaged 2.4 times/day during the 2-year study. Animals entered the scales to drink water during all hours of the day or night. There were, however, 3 distinct time blocks that accounted for $44 \%$ of all observations (Fig. 1). They were 0700 to 0800 (15\%), 1100 to 1200

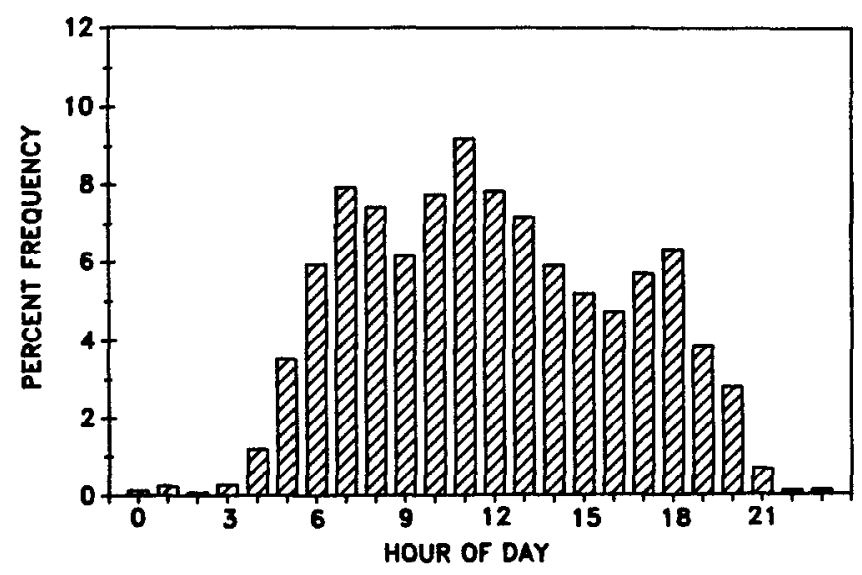

Fig. 1. Percent frequency of automatic scale unit use by hour of day (MST) during 1986 and 1987 summer grazing periods.

(17\%), and 1700 to $1800(12 \%)$ hr MST. These periods of scale use varied slightly over the summer with the corresponding changes in time of sunrise and sunset and other environmental conditions.

Steers were observed to have less grazing activity and rested more near the scale units with the warmer mid-day and afternoon temperatures of late July and August. Also, the steers used in 1986 tended to be more active in the early morning hours compared to those used in 1987. They used the scales more often from 0500 to $0600 \mathrm{hr}$. This was possibily related to differences in environmental factors in the 2 years. Our pastures were, however, relatively small ( $12 \mathrm{ha}$ ), and the observed behavior and patterns of use might have been different on larger pastures. Such effects will receive further scrutiny as additional data become available.

\section{Live Weight Gains}

Minimum estimates of live weight generally occurred before noon for all animals and was the first record stored before any water consumption took place. Minimum daily live weights had less day-to-day variation than weights based on averages of all weights recorded or the maximum daily live weights. Hughes and

Harker (1950) reported that weighing after a 16-hour fast resulted in the lowest day-to-day variation in live weight, but weighing 3 hours after sunrise was almost as good.

In 1986, the linear relationship between live weight and Julian date was significant $(P<0.01)$ (Fig. 2). The quadratic fit was also significant and the $R^{2}$ value was increased from 0.59 to 0.88 . A plateau in live weight occurred on day 215 (3 August) and then a marked decrease began about 10 days later and continued through the remainder of the grazing period. The amount of live weight loss from the peak live weight to the end of the grazing period averaged $8.3 \mathrm{~kg}$.

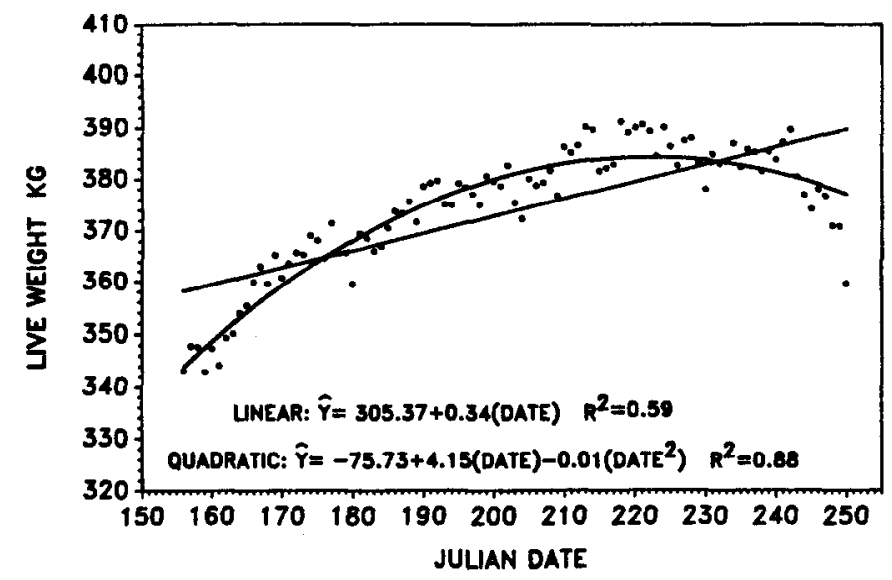

Fig. 2. Linear and quadratic relationships of mean minimum daily live weight and Julian date for 40 yearling steers, 1986.

Linear and quadratic relationships based on the 1987 data were also significant $(P<0.01)$ (Fig. 3). The $R^{2}$ value was increased from 0.80 to 0.90 using the quadratic model. Predicted live weights of the 1987 steers based on the quadratic fit plateaued on about day 225 (12 August) followed by a slight decrease at the end of the grazing period. The amount of live weight loss from the peak live weight to the end of the grazing period averaged only $1.4 \mathrm{~kg}$.

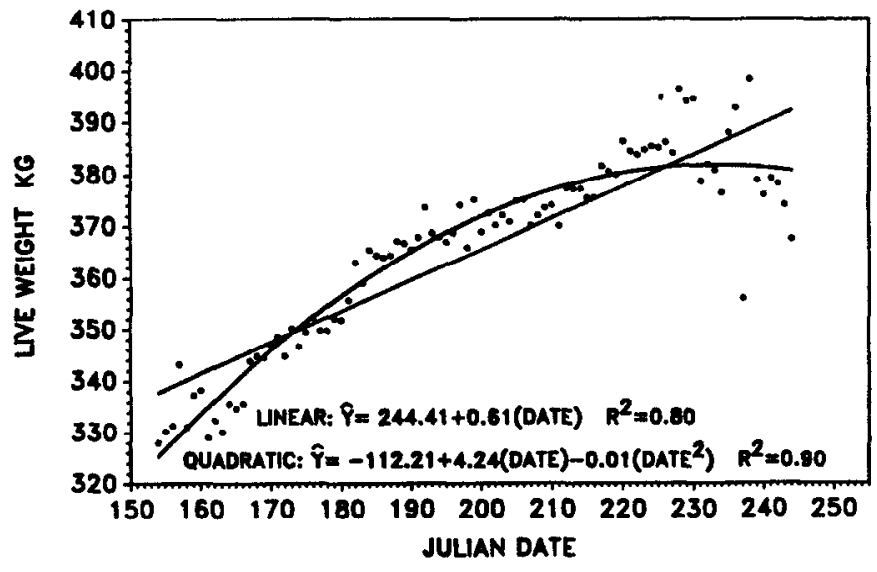

Fis. 3. Linear and quadratic relationships of mean minimum daily live weight and Julian date for 40 yearling steers 1987.

Differences in grazing pressure between years was probably the major factor causing differences in live weight gains. Although total growing season precipitation was similar in both years, mid 
growing season (July) precipitation was $82 \%$ greater in 1987 compared to 1986. As a result, we assume both quantity and quality of forage during the latter portion of the 1987 growing season was greater than in 1986; thus, live weight gains were greater in 1987 than 1986 (Figs. 2 \& 3).

\section{Dally Variabllity}

The automatic weighing of steers showed that within-day variability of live weight was substantial. For example, typical fluctuations in daily live weight of steer $62-002$ are shown in Figure 4 . The average range (high minus low) of daily live weight for this steer

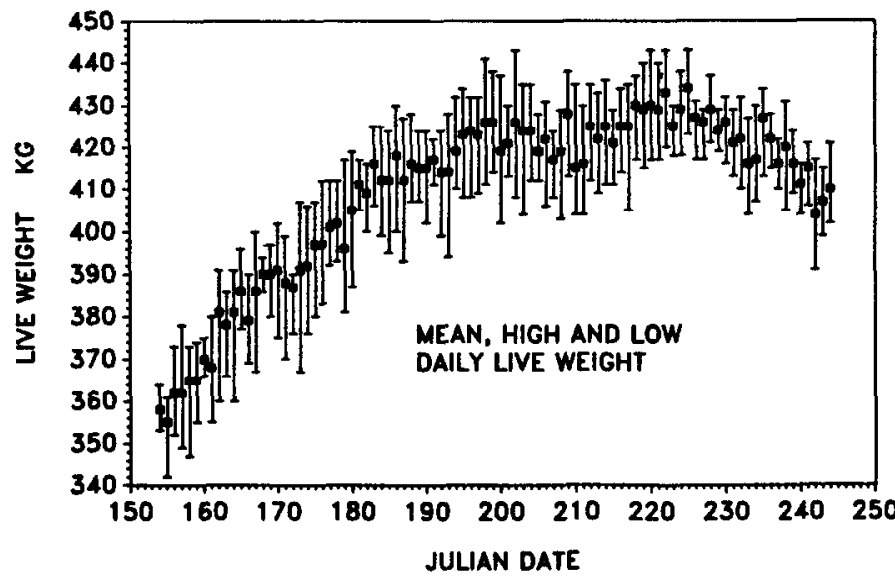

Fig. 4. Fluctuations in daily live weight of a free-ranging yearling steer (No. 62-002), 1987.

was $22.4 \mathrm{~kg}$. The maximum range was $40 \mathrm{~kg}$ and occurred on day 173 (22 June). This 40-kg change in live weight was associated with a total water intake of 34.5 liters or $34.5 \mathrm{~kg}$ in weight of water consumed over 4 drinking events throughout the day plus an unknown amount of forage intake minus defecation and urination loss. The greatest daily range in live weight occurred between days 166 and 196 (15 June to $15 \mathrm{July}$ ) and averaged $25.3 \mathrm{~kg}$ during this period. In contrast, the range in August was $19.4 \mathrm{~kg}$. It is hypothesized that the greater daily live weight range during mid-June to mid-July was due to a more rapid passage of forage and fluids from the rumen. Fluid and particulate passage rates from the rumen are greater for immature than mature forages (Galyean 1987). This period was also the time of the greatest rate of daily gain. Dry matter content of the forage available in August was substantially higher and rate of daily gain very low.

As depicted in Figure 4, the minimum daily live weight of steer 62-002 was recorded during the first drinking event of the day $81 \%$ of the time. The first drinking event generally occurred before 1000 hr. The mean daily live weight, calculated from all high and low weights recorded, tended to be closer to the highest weight because of the influence of grazing fill and previous water intake as the animal entered the scale for water later in the day.

Observed variability of within-day live weight also showed the need for caution when establishing weighing schedules with conventional equipment. Hart (1987) reported variations in live weight of grazing animals appear to be cyclic and related to grazing patterns. Our data would indicate patterns of water consumption are also important.

\section{Conventional vs. Automatic Scale Weighing}

Comparisons of steer live weights taken manually on a conventional electronic scale and those recorded on the same day by the automatic scales are given in Table 1. Correlations of live weights from the 2 different weighing systems was very high with correlation coefficients ( $r$ ) of 0.85 and 0.87 in 1986 and 1987 , respectively.
Table 1. Comparicon of teer mean live welghts (ks) \pm standard error (SE) determined uning automatic and conventional seales during July, 1986 and 1997.'

\begin{tabular}{llll}
\hline \hline Date & \multicolumn{2}{c}{ Automatic scale } & $\begin{array}{c}\text { Conventional } \\
\text { scale }\end{array}$ \\
\hline & Minimum & Maximum & \\
25 July 1986 & $372 \pm 13$ & $383 \pm 14$ & $392 \pm 18$ \\
17 July 1987 & $368 \pm 9$ & $380 \pm 9$ & $376 \pm 9$ \\
\hline
\end{tabular}

'Conventional scale live weights were taken between 0900 and $1100 \mathrm{hr}$ (MST).

Average live weight measurements from conventional weighing, however, were 20 and $8 \mathrm{~kg}$ higher than daily minimums from the automatic scales during 1986 and 1987 , respectively. This is as would be expected because conventional scale weights were taken between 0900 and $1100 \mathrm{hr}$ and all steers would have had the opportunity to graze and/or consume water prior to the time of being conventionally weighed. This is in agreement with the findings of Heitschmidt (1982), who reported early morning live weights of mature range cows to be about $2.5 \%$ less than late morning live weights. The maximum automatic scale live weight was $9 \mathrm{~kg}$ less than the conventional scale live weight in 1986 and 4 kg greater in 1987.

Calculated average daily gain (ADG) based on the conventional scale weights showed marked differences between the first and second half of the grazing seasons in both 1986 and 1987 and reflected a pattern of animal performance measured since the study was started in 1983 (Table 2). Second half ADG calculated from

Table 2. Average daily gains (kg/d) of yearling steers during the first half, second half, and entire graxins period.

\begin{tabular}{lccc}
\hline \hline Year $^{1}$ & First half & Second half & Entire period \\
\hline 1983 & 1.06 & 0.23 & 0.65 \\
1984 & 1.44 & 0.34 & 0.89 \\
1985 & 1.02 & 0.54 & 0.78 \\
1986 & 1.13 & -0.36 & 0.39 \\
1987 & 1.27 & 0.13 & 0.70 \\
\hline Mean & 1.18 & 0.18 & 0.68 \\
\hline
\end{tabular}

${ }^{1} 1983$ and 1987 grazing period length $=90$ days.

1984 grazing period length $=60$ days.

1985 grazing period length $=40$ days.

1986 grazing period length $=96$ days.

the conventional scale live weights were -0.36 and $0.13 \mathrm{~kg} / \mathrm{d}$ in 1986 and 1987, respectively. A similar trend of reduced weights in the second half of the season were also measured in 1983, 1984, and 1985. Thus, these data indicated that rates of gain based on a relatively long weighing interval mask the true picture, as interpreted from the daily live weights measured by the automatic scales (Fig. 2 and 3). These differences in ADG between periods can also be calculated and interpreted from the predicted growth curve lines generated with the daily live weight data from the automatic scales. More importantly, however, the automatic scales allows one to define a growth curve line and discern the specific days when the live weight changes begin to plateau and decline, or correspondingly, when the ADG is at or below zero.

\section{Management Implications}

Daily live weight estimates obtained by the use of automatic scales allowed development of more precise growth patterns for free-ranging yearling steers than can be obtained by conventional weighing methods. The regression lines developed allowed us to specifically identify points in time when live weight was leveling out, increasing or decreasing. From a livestock management per- 
spective for yearling steers, these weight estimates defined when a decision should be made. It suggested this may be the time when the producer should provide supplemental feed or remove the animals from pasture and place them in a feedlot. Otherwise decreasing weight gain performance can be expected. With the rather narrow margin profit or loss margin frequently encountered by livestock producers, this decision can have a significant impact on relative success of a livestock operation.

From a research perspective, the potential within-day variability of live weight re-emphasizes the need for caution when interpreting infrequent live weight data, especially in light of the temporal pattern associated with events such as drinking. Also, data obtained by the use of the automatic scales and complemented with appropriate climatic and forage quality and quantity data will allow development of comprehensive models to quantitatively describe growth of free-ranging animals under a variety of conditions.

\section{Literature Cited}

Adams, D.C., P.O. Currie, B.W. Knapp, T. Mauney, and D. Richardson. 1987. An automated range-animal data acquisition system. J. Range Manage. 40:256-258.

Anderson, D.M., J.A. Landt, and P.H. Salazar. 1981. Electronic weighing, identification and subdermal body temperature sensing of range livestock. p. 373-382. In: J.L. Wheeler and R.D. Mochrie (eds.), Forage Evaluation: Concepts and Techniques, CSIRO and Amer. Forage and Grassl. Counc., Melbourne, Australia.

Anderson, D.M., and G. Tietjen. 1982. Drylot shrink of cattle grazing semidesert rangeland during February, May, July and October. Proc. Western Section, Amer. Soc. Anim. Sci. 33:242-245.

Currie, P.O., and J.D. Volesky. 1987. Effects of multiple range renovation practices on forage production and animal performance. Fort Keogh Livestock and Range Research Station Field Day, Miles City, Mont., 14 Sept., 1987 p. 3-7.
Erickson, L.R., and P.O. Currie. 1985. Rangeland improvement machine for multiple renovation practices on semi-arid rangelands. Trans. Amer Soc. Agr. Eng. 28:94-96.

Galyean, M.L. 1987. Factors influencing digesta flow in grazing ruminants. p. 77-89. In: Proc., Grazing Livestock Nutrition Conference, 23-24 July, 1987, Jackson, Wyo.

Hart, R.H., and J.W. Wagzoner, D.H. Clark, C.C. Kaltenbach, J.A. Hager, and M.B. Marshall. 1983. Beef cattle performance on crested wheatgrass plus native range vs. native range alone. J. Range Manage. 36:38-40.

Hart, R.H. 1987. Monitoring changes in animal weights. p. 37-39, In Monitoring Animal Performance and Production Symp. Proc., 12 Feb., 1987, Boise, Ida., Soc. Range Manage., Denver, Colo.

Heitschmidt, R.K. 1982. Diurnal variation in weight and rates of shrink of range cows and calves. J. Range Manage. 35:717-720.

Hughes, J.G. 1976. Short-term variation in animal live weight and reduction of its effect on weighing. Anim. Breeding Abstr. 44:111-118.

Hughes, J.G., and K.W.Harker. 1950. The technique of weighing bullocks on summer grass. J. Agr. Sci. 40:403-409.

Johnson, W.M., and W.A. Laycock. 1963. Kind, number and selection of livestock for grazing studies, and animal measurement most suited for evaluating results. p. 137-142. In: Range Research Methods. USDA Misc. Pub. 940.

Jung, H.G., R.W. Rice, and L.J. Koong. 1985. Comparison of heifer weight gains and forage quality for continuous and short-duration grazing systems. J. Range Manage. 38:144-148.

Lush, J.L., and W.H. Black. 1927. How much accuracy is gained by weighing cattle three days instead of one at the beginning and end of the feeding experiment. Proc. Amer. Soc. Anim. Prod. 1925-1926:206-210.

Volesky, J.D. 1986. A comparison of high-performance short-duration and repeated-seasonal grazing systems. Ph.D. Diss., S. Dakota State Univ., Brookings. 